\title{
Employment status and differences in physical activity behavior during times of economic hardship: results of a population-based study
}

\author{
Gloria Macassa ${ }^{1-3}$, Nader Ahmadi ${ }^{4}$, Johana Alfredsson ${ }^{5}$, Henrique Barros ${ }^{6}$, Joaquim Soares², \\ Mindaugas Stankunas ${ }^{7}$ \\ 'Department of Occupational and Public Health Science, University of Gävle, Kungsbäcksvägen, Gävle, Sweden. \\ ${ }^{2}$ Department of Health Science, Mid-Sweden University, Sweden. \\ ${ }^{3}$ Department of Public Health Sciences, Karolinska Institute, Solnavägen, Solna, Sweden. \\ ${ }^{4}$ Department of Social Work and Psychology, University of Gävle, Kungsbäcksvägen, Gävle, Sweden. \\ ${ }^{5}$ Department of Community Medicine, Gävleborg County Council, Sweden. \\ ${ }^{6}$ Department of Hygiene and Epidemiology, University of Porto Medical School, Portugal. \\ ${ }^{7}$ Department of Health Management, Lithuanian University of Health Sciences, Lithuania. \\ Correspondence to: Gloria Macassa, E-mail: glamaa@hig.se
}

Received January 1, 2015. Accepted June 23, 2015

\section{Abstract}

Background: The recent economic recession has lead to an increased unemployment in many countries worldwide. In addition, research has suggested that economic recession can have an impact on an individual's health behaviors, including engagement in physical activity. Gävleborg County in southeast Sweden, experienced massive job losses owing to the closures of large industries and small companies, which resulted in an increased unemployment rate in 2010 , at the pick of the economic recession.

Objective: To investigate the differences in physical activity by employment status among economically active persons living in Gävleborg County in 2010.

Materials and Methods: The data were obtained from a cross-sectional survey carried out in Gävleborg County, in 2010, among the residents aged 16-65 years $(n=4,245)$. Data analysis was carried out using descriptive statistics and weighted logistic regression.

Result: There was a statistically significant association between employment status and physical activity. People who were not employed in 2010 showed higher odds of physical inactivity when compared with their employed counterparts. The differences in physical activity behavior were explained, mainly, by health and socioeconomic and related factors.

Conclusion: Being outside the labor market was associated with increased physical inactivity during a period of economic recession in Gävleborg County. From a policy perspective, our study suggests the need to promote physical activity during times of high unemployment in order to foster better health behaviors.

KEY WORDS: Gävleborg, employment status, physical activity, economic recession

\begin{tabular}{|l|c|}
\hline \multicolumn{2}{|c|}{ Access this article online } \\
\hline Website: http://www.ijmsph.com & Quick Response Code: \\
\hline DOl: 10.5455/ijmsph.2016.0101201515
\end{tabular}

\section{Introduction}

Available research has found that being physically active might be important to improve overall health, as it can help in preventing adverse health outcomes and chronic diseases such as coronary heart disease, stroke, type 2 diabetes, osteoporosis, and depression..$^{[1,2]}$

As a result of the economic downturn and recession, which started in the autumn of 2008 , many countries started

International Journal of Medical Science and Public Health Online 2016. ( 2016 Gloria Macassa. This is an Open Access article distributed under the terms of the Creative Commons Attribution 4.0 International License (http://creativecommons.org/licenses/by/4.0/), allowing third parties to copy and redistribute the material in any medium or format and to remix, transform, and build upon the material for any purpose, even commercially, provided the original work is properly cited and states its license. 
to experience increased unemployment. ${ }^{[3,4]}$ It is suggested that economic recession can impact on an individual's health behaviors, including the engagement in physical activity. ${ }^{[5]}$ Moreover, across OECD countries and in Europe, empirical evidence has shown that unemployed people experienced high mortality ${ }^{[6]}$ and poor physical and mental health. ${ }^{[7]}$ However, others have found contrary results regarding this relationship. ${ }^{[8,9]}$

In the majority of the studies, unemployment has been found to be detrimental to health behavior. ${ }^{[6,10,11]}$ Furthermore, some authors argue that an economic downturn may reduce nutrition quality and physical activity, thus worsening obesity prevalence when society is least able to bear the escalating financial burden. ${ }^{[5,12-15]}$

Several hypotheses have been put forward by different scholars on the potential links between economic conditions and physical activity. Some scholars suggest that, during an economic crisis, people experience excessive financial and psychological stresses, which can contribute to a sedentary lifestyle and decreased level of physical activity. ${ }^{[1]}$ Furthermore, it is believed that both the physical and social environments play an important role, as neighborhoods deteriorate during recessions, which in turn discourages residents from engaging in physical activity. ${ }^{[16]}$ Moreover, others state that the relationship between economic conditions and physical activity is related to time use-a reduction of hourly wages during recessions (or even the absence of paid work options) lowers the incentive for people to increase leisure-time activities including physical activity. ${ }^{[15]}$ But, the relationship among economic recession, unemployment, and physical activity remains a subject of continuing debate. For instance, using individual-level data from the Behavioral Risk Factor Surveillance System 1987-2000 waves, Ruhm ${ }^{[17]}$ found an increase in physical activity when state labor market conditions worsened. In addition, Charles and DeCicca ${ }^{[18]}$ observed no association between unemployment rate and physical activity among respondents from high-risk jobs.

In Sweden, few studies have accessed the relationship between employment status and physical activity in times of recession. In addition, available studies have found mixed results. ${ }^{[19,20]}$ For instance, Lindström et al. ${ }^{[19]}$ reported that self-employed male and female pensioners showed a significantly increased risk of low-leisure time physical activity, but found no difference in odds among skilled and unskilled manual workers compared with high-level nonmanual employees. They also argued that some of the socioeconomic differences in leisure-time physical activity were owing to differences in social capital between socioeconomic groups. ${ }^{[19]}$

The context of this study is Gävleborg County, in East Central Sweden, where the recent economic crises caused increased levels of unemployment compared with the national average. At its peak, the rate of unemployment among people aged $16-84$ years was $13.8 \%$ in 2010 compared with $7.0 \%$ for the national average. ${ }^{[21]}$ The massive unemployment experienced by the county has been blamed on the closures of large industries and small companies distributed across the county. Furthermore, the County of Gävleborg showed the lowest percentage of highly educated people among those economically active in the entire country $(29 \%$ in 2010). ${ }^{[22]}$

Regarding lifestyle of the county's population, it was found that in $2010,39 \%$ of the population was not physically active (as measured by 30 min of physical activity per day) and $15 \%$ did not engage in any physical activity. In addition, 16\% of the population was considered obese with a body mass index (BMI) of $30 \mathrm{~kg} / \mathrm{m}^{2}$ and more, and only $30 \%$ ate at least one fruit a day. ${ }^{[22]}$ Although the economic crisis affected the county severely, to our knowledge, no study has attempted to investigate its impact on people's health behaviors and, specifically, regarding physical activity. Therefore, this study aims to investigate differences in physical activity by employment status among people residing in Gävleborg County in 2010.

\section{Materials and Methods}

\section{Study Design and Procedure}

The subjects of this study come from the Health in Equal Terms (HET) Survey, a cross-sectional study carried out in 2010 in Gävleborg County. The sample selection was carried out by Statistics Sweden, and the sampling frame has been created based on the Total Population Register, which consists of all the registered residents within the county between the ages of 16 and 84 years, in total 221,618 individuals.

\section{Inclusion Criteria}

All people aged 16-84 years residing in Gävleborg County during 2010 were included.

\section{Exclusion Criteria}

People who were aged $16-84$ years who did not return the post mail questionnaires or did not answer the Web questionnaires at the time of the survey in 2010 were excluded.

A sample of 11,977 individuals was selected with approximately 1,000 individuals by municipality and 600 individuals in Gävle Municipality, the administrative center of the county. Overall, 5,983 persons aged 16-84 years completed the questionnaire resulting in a response rate of $50 \%$ [Table 1]. However, for this study, only people in economically active ages $(16-65$ years) were included $(4,245)$.

The survey was carried out by the Swedish National Institute in collaboration with Gävleborg County Council, and data collection was conducted by Statistics Sweden. Respondents were able to participate in the survey by completing either a postal or a Web questionnaire. Information was enclosed with the questionnaire that was sent to the selected individuals regarding the study's background and objectives, how the answers would be used, and data would also be retrieved from the Total Population Register (for variables such as education, income, and taxation). The questionnaire collected background demographic and socioeconomic variables, variables regarding health, lifestyle, economic conditions, labor market, and employment and regarding security and socia relationships. 
Table 1: Questionnaire flow in the Gävleborg County's Health in Equal Terms Survey 2010

\begin{tabular}{lcc} 
& Number & Percentage \\
\hline Population of Gävleborg County & 221,618 & Total population \\
Selected sample for the Health and Equal & 11,977 (16-84 years) & 100 \\
$\quad$ & & 50 \\
Terms Survey, 2010 & $5,983(16-84$ years $)$ & 50 \\
Number of returned questionnaires & $5,994(16-84$ years $)$ & Sample included in the descriptive and binary logistic regressions \\
Sample included in this study & $4,245(16-65$ years $)$ &
\end{tabular}

\section{Measurement of Variables \\ Outcome Variable}

In this study, the outcome variable was physical activity. Physical activity was measured with the question: "How much have you moved and exerted yourself physically in your spare time during the past 12 months?" In the survey, the answers were divided into three categories: "low," "moderate," or "vigorous" physical activity. For the purposes of this study, the variable was dichotomized using a "yes" and "no" format. Those who reported moderate to vigorous physical activity were coded yes, and those who reported none to low physical activity as no.

\section{Independent Variables}

The main independent variable in this study is employment status. In the survey, employment status was assessed with one question, "What is your current main job?" The answers were dichotomized into two categories; employed and not employed. The employed group included people who were employed and those on parental leave (with employment). The group of not employed included the unemployed, students, and those who were inactive, such as the elderly people and those with disability.

Other independent variables (potential confounders) were sex, age group (16-29, 30-44, 45-64, and 65-84) years, marital status (married, unmarried, and widowed), education, income, social support, smoking habits, and self-reported health.

Education was assessed by using Statistics Sweden's educational register from 2009. The classification is made for the person's highest level of education according to Swedish educational nomenclature (SUN) 2000. For this study, three levels of education were created: primary school or similar, secondary school/similar, and university/similar.

Income data were collected from income and taxation registers (related to 2008) as total individual income, and three groups were created: (a) low income, $<250,000$ SEK, (b) medium income, 250,000-750,000 SEK, and (c) high income, $>750,000$ SEK a year.

Social support was measured with the question: "Do you have someone you can share your deepest feelings with and confide in?" There were two possible answers that distinguish those with social support (yes) from those without social support (no).

Self-rated health was assessed with the question "How do you rate your general health?" with the options "very good," "good," "neither good nor poor," "poor," and "very poor." In the analysis, the categories very good and good were combined as good health, and the categories neither good nor poor, poor, and very poor were combined as poor health.

Smoking habits were assessed by the following questions: (a) "Do you smoke daily?" (b) "Does it happen that you smoke every now and then?" and (c) "Have you before smoked daily for at least six months?" Each of the questions could be answered with yes and no. In this study, smoking habits were divided into three groups: daily smokers, individuals who had stopped smoking, and those who had never smoked.

Risky consumption of alcohol was assessed by three questions: (a) "How often have you drunk alcohol in the past 12 months?" (b) "How many "glasses" (example was given) do you drink on a typical day when you drink alcohol?" and (c) "How often do you drink six "glasses" or more on the same occasion?" A new composite variable was used for this study and was categorized as yes (risk consumption) and no (no-risk consumption).

\section{Statistical Analysis}

The analyses consisted of descriptive statistics (frequencies) and weighted logistic regression analysis, which was carried out fitting four different models. The first model (model I) included the relationship between employment status and physical activity only. The second model (model II) added demographic variables; model III added health-related variables. The final model (model IV) added socioeconomic variables. The results of the logistic regressions are present as odds ratios (OR) with $95 \%$ confidence intervals (Cls). All analyses were carried out using SPSS software, version 20. ${ }^{[23]}$

\section{Ethical Approval}

This study was approved by the Ethics Committee of the Swedish National Institute of Public Health and the Regional Ethical Committee in Uppsala and performed in compliance with the Helsinki Declaration. Verbal informed consent was obtained from all participants.

\section{Result}

The distribution of the variables included in the study sample is presented in Table 2. There were 57.2\% $(n=2,427)$ subjects who reported no or low physical activity and $41.7 \%$ ( $n=1,770)$ with moderate to vigorous physical activity. The 
Table 2: Sample and percentage distribution of the individual variables included in the analysis, Health in Equal Terms Survey Gävleborg, 2010

\begin{tabular}{|c|c|c|}
\hline Variables & $N(4,245)$ & Percentage \\
\hline \multicolumn{3}{|l|}{ Physical activity } \\
\hline No & 2,427 & 57.2 \\
\hline Yes & 1,770 & 41.7 \\
\hline Missing & 48 & 1.1 \\
\hline \multicolumn{3}{|l|}{ Employment status } \\
\hline Employed & 2,350 & 55.4 \\
\hline Not employed & 1,389 & 32.7 \\
\hline Missing & 506 & 11.9 \\
\hline \multicolumn{3}{|l|}{$\begin{array}{l}\text { Demographic variables } \\
\text { Sex }\end{array}$} \\
\hline Male subjects & 1,915 & 45.1 \\
\hline Female subjects & 2,330 & 54.9 \\
\hline \multicolumn{3}{|l|}{ Age group (years) } \\
\hline $16-25$ & 575 & 13.5 \\
\hline $26-35$ & 488 & 11.5 \\
\hline $36-45$ & 816 & 19.2 \\
\hline $46-55$ & 1,022 & 24.1 \\
\hline $56-65$ & 1,344 & 31.7 \\
\hline \multicolumn{3}{|l|}{ Marital status } \\
\hline Married & 1,808 & 42.6 \\
\hline Single & 2,374 & 55.9 \\
\hline Widowed & 63 & 1.5 \\
\hline \multicolumn{3}{|l|}{ Socioeconomic variables } \\
\hline \multicolumn{3}{|l|}{ Education } \\
\hline Primary school or similar & 871 & 20.5 \\
\hline Secondary school/similar & 2,318 & 54.6 \\
\hline University/similar & 1,006 & 23.7 \\
\hline Missing & 50 & 1.2 \\
\hline \multicolumn{3}{|l|}{ Income } \\
\hline$<250$ th SEK & 908 & 21.4 \\
\hline 250-750th SEK & 2,038 & 48 \\
\hline >750th SEK & 1,282 & 30.2 \\
\hline Missing & 17 & 0.4 \\
\hline \multicolumn{3}{|l|}{ Social support } \\
\hline Yes & 3,712 & 87,4 \\
\hline No & 467 & 11 \\
\hline Missing & 66 & 1.6 \\
\hline \multicolumn{3}{|l|}{ Health-related variables } \\
\hline \multicolumn{3}{|l|}{ Self-rated health } \\
\hline Good & 2,975 & 70.1 \\
\hline Poor & 1,194 & 28.1 \\
\hline Missing & 76 & 1.8 \\
\hline \multicolumn{3}{|l|}{ Smoking habits } \\
\hline Yes & 714 & 16.8 \\
\hline No & 3,140 & 74 \\
\hline Missing & 391 & 9.2 \\
\hline \multicolumn{3}{|l|}{ Risky consumption of alcohol } \\
\hline No & 3,473 & 81.8 \\
\hline Yes & 731 & 17.2 \\
\hline Missing & 41 & 1 \\
\hline
\end{tabular}

majority of the individuals in the sample were in the age group of 44-64 years (41\%) and $49.8 \%$ completed secondary school/similar education.

The results of the bivariate analysis (model I) showed a statistically significant relationship between employment status and low physical activity. Compared with people who were employed and with moderate to vigorous activity, those who were not employed had OR of $1.54(95 \% \mathrm{Cl}: 1.31-1.73)$ [Table 3].

Adjusting for demographic variables in model II (sex, age, and marital status) and for health and health behavior variables in model III (self-rated health smoking habits and risky alcohol consumption) reduced only slightly the risk of physical inactivity from $1.54(95 \% \mathrm{Cl}$ : $1.31-1.73)$ to $1.53(95 \% \mathrm{Cl}: 1.30-1.34)$ and to $1.45(95 \% \mathrm{Cl}: 1.20-1.50)$, respectively [Table 3]. But, the relationships remained statistically significant.

Controlling for socioeconomic variables (education, income, and social support) in model IV further reduced the odds of the relationship between unemployment and physical inactivity, and the statistical significance disappeared. The OR reduced from $1.54(95 \% \mathrm{Cl}: 1.31-1.73)$ in model I to 1.01 (95\% Cl: 0.85-1.21) in model IV [Table 3]. In addition, people who were not employed with primary school or similar education and those with an annual income lower than 250,000 SEK revealed increased odds of low physical activity of $1.65(95 \% \mathrm{Cl}: 1.65-2.01)$ and $1.74(95 \% \mathrm{Cl} 1.37-2.22)$. Furthermore, results showed that people who were out of work and reported poor health showed higher odds of physical inactivity of $2.21(95 \% \mathrm{Cl}: 1.91-2.56)$ [Table 3 model IV].

\section{Discussion}

This study has found a relationship between employment status and physical inactivity, and the relationship was explained mainly by health-related and socioeconomic factors. Similar results have been found in other studies ${ }^{[24,25]}$ from a variety of contexts, in times of relative economic prosperity. For instance, a study concerning correlates and predictors of physical activity over time observed that income and education showed a strong and consistent positive effect on physical activity. ${ }^{[25]}$ Another study carried out in the United Kingdom found that people with upper secondary school-level qualifications or above were more likely to take part in regular exercise, whereas, those with lower second-level education or less were five times less likely to play sports than those with third-level education. ${ }^{[26]}$ In addition, Owen et al. reported that adult participation in physical activity was influenced by a range of personal, social, and environmental factors and those individual level variables such as socioeconomic status and perceived self-efficacy demonstrated the strongest association with physical activity behavior. ${ }^{[27,28]}$ However, other studies have reported contradictory results. For instance, a study concerning the relationship between physical activity and socioeconomic status reported that the statistical significance observed was totally eliminated when physical activity 
Table 3: Odds ratios (ORs) with $95 \%$ confidence intervals $(\mathrm{Cl})$ of the relationship between employment status and physical inactivity, Health in Equal Terms Survey, Gävleborg, 2010

\begin{tabular}{|c|c|c|c|c|}
\hline Variable & Model I & Model II & Model III & Model IV \\
\hline \multicolumn{5}{|l|}{ Employment status } \\
\hline Employed & Reference & Reference & Reference & Reference \\
\hline Not employed & $1.54(1.31-1.37)$ & $1.53(1.30-1.64)$ & $1.45(1.20-1.50)$ & $1.01(0.85-1.21)$ \\
\hline \multicolumn{5}{|l|}{ Demographic variables } \\
\hline \multicolumn{5}{|l|}{ Sex } \\
\hline Male subjects & - & Reference & Reference & Reference \\
\hline Female subjects & - & $1.02(0.78-1.45)$ & $1.02(0.78-1.45)$ & $1.02(0.77-1.43)$ \\
\hline \multicolumn{5}{|l|}{ Age group (years) } \\
\hline $16-25$ & - & $2.28(1.94-2.92)$ & $2.24(1.84-2.70)$ & $1.91(0.94-1.90)$ \\
\hline $26-35$ & - & $1.54(1.25-1.90)$ & $1.45(1.16-1.64)$ & $1.45(0.16-1.64)$ \\
\hline $36-45$ & - & $1.41(1.18-1.68)$ & $1.40(1.18-1.67)$ & $1.35(0.57-1.68)$ \\
\hline $46-55$ & - & $1.32(1.11-1.56)$ & $1.31(1.11-1.56)$ & $1.21(0.50-1.50)$ \\
\hline $56-65$ & - & Reference & Reference & Reference \\
\hline \multicolumn{5}{|l|}{ Marital status } \\
\hline Married & - & Reference & Reference & Reference \\
\hline Single & - & $1.05(0.91-1.22)$ & $1.05(0.90-1.21)$ & $1.05(0.90-1.21)$ \\
\hline Widowed & - & $1.26(0.92-1.72)$ & $1.26(0.91-1.71)$ & $1.26(0.91-1.71)$ \\
\hline \multicolumn{5}{|l|}{ Health-related variables } \\
\hline \multicolumn{5}{|l|}{ Self-rated health } \\
\hline Good & - & - & Reference & Reference \\
\hline Poor & - & - & $2.21(1.91-2.56)$ & $1.20(0.86-2.20)$ \\
\hline \multicolumn{5}{|l|}{ Smoking habits } \\
\hline Yes & - & - & $0.53(0.44-1.28)$ & $0.51(0.40-1.27)$ \\
\hline No & - & - & Reference & Reference \\
\hline \multicolumn{5}{|l|}{ Risky consumption of alcohol } \\
\hline No & - & - & Reference & Reference \\
\hline Yes & - & - & $0.91(0.77-1.01)$ & $0.90(0.78-1.01)$ \\
\hline \multicolumn{5}{|l|}{ Socioeconomic variables } \\
\hline \multicolumn{5}{|l|}{ Education } \\
\hline Primary school or similar & - & - & - & $1.65(1.35-2.01)$ \\
\hline Secondary school/similar & - & - & - & $1.53(1.31-1.80)$ \\
\hline University/similar & - & - & - & Reference \\
\hline \multicolumn{5}{|l|}{ Income } \\
\hline$<250$ th SEK & - & - & - & $1.74(1.37-2.22)$ \\
\hline 250-750th SEK & - & - & - & $1.30(1.1-1.53)$ \\
\hline$>750$ th SEK & - & - & - & Reference \\
\hline \multicolumn{5}{|l|}{ Social support } \\
\hline Yes & - & & & Reference \\
\hline No & - & & & $1.01(0.81-1.28)$ \\
\hline
\end{tabular}

was conducted around the home and at work, which would indicate the importance of the context where the activity took place. ${ }^{[29]}$ In a recent study, going beyond just the relationship between income and physical activity, Hyytinen and Lahtonen $^{[30]}$ found that long-term income of physically active male subjects was approximately $14 \%-17 \%$ higher than that of less active male subjects.

Unemployment is a permanent stress situation requiring the person to adapt. The unemployed persons are in a very difficult situation, exacerbated by their social marginalization and own sense of failure, in turn, leading to feelings of worthlessness. ${ }^{[9]}$
Many argue that the stress experienced by unemployed people might be the underlying cause of unhealthy behavior. The stress hypothesis stipulates that job loss causes psychological distress and unhealthy behavior. ${ }^{[9]}$ In addition, medical studies have found that stress increases both eating and smoking. ${ }^{[31-34]}$ Moreover, job loss affects health behavior through an income effect.

In our study, controlling for socioeconomic variables such as education, income, and other health variables (smoking and self-reported health) eliminated the statistically significant relationship between employment status and physical inactivity. In 2010, the time the data for this study was collected, 
there was a massive loss jobs (with income loss), which might have caused financial strain with possible adverse effects in health behaviors (including physical activity). Furthermore, a further indication of the role of income is seen in Table 2 where respondents who were not employed with an annual income lower than 250,000 SEK a year revealed increased odds of physical inactivity of $1.74(95 \% \mathrm{Cl}: 1.37-2.22)$ [Table 3].

We also found that age, gender, marital status, and social support were not associated with physical activity. However, studies carried out elsewhere have found different results. In relation to gender and age, some studies have found that participation in physical activity was consistently higher in men than women and inversely associated with age. ${ }^{[33]}$ In addition, mixed results have been reported in regard to the relationship between physical activity and marital status. ${ }^{[33]}$

Concerning social support, several studies have found it to be associated with levels of physical activity. ${ }^{[35,36]}$ For instance, Resnick et al. reported that friends support indirectly influenced exercise through self-efficacy and outcome. In the view of the authors, interventions aimed to improve exercise behavior in adults and especially older adults should incorporate social support to strengthen self-efficacy expectation outcomes. ${ }^{[36]}$

We found that smoking was not statistically significantly associated with physical activity. However, other studies have reported that, compared with inactive individuals, physically active individuals smoked fewer cigarettes and were more likely to be nonsmokers or occasional smokers. ${ }^{[37,38]}$ The differences in results regarding the relationship between smoking and physical activity might be related to the fact that the studies carried out in Cyprus and Greece assessed populations of adolescents and young adults (19-30 years of age) when compared with 16-65 years of age, which was the target age in our sample.

Furthermore, our study did find a relationship between self-reported health and physical activity [Table 3]. This result is in line with findings from a European study carried out in 2004 in 15 member states. The authors reported a positive relationship between physical activity and self-rated health across population subgroups as divided by age, gender, income, and educational attainment. ${ }^{[39]}$ However, Ker et al. ${ }^{[40]}$ observed that older adults who were physically active outdoors accumulated significantly more physical activity, but self-rated health was not significantly greater than those being physically active indoors. BMI was not associated with employment status (results not shown).

\section{Strengths and Limitations}

This study used a cross-sectional design, which makes it difficult to estimate causal relationships between unemployment and physical activity and their direction. In addition, some authors have stressed the difficulties of measuring physical activity, which in turn can cause problems with inter pretation of findings. ${ }^{[41]}$ In addition, the response rate in the study was around $50 \%$, which is similar to response rates in Swedish population-based surveys. ${ }^{[42,43]}$ However, the response rate is unlikely to have influenced the results.
As mentioned earlier, Statistics Sweden collected the data and applied population weightings to estimate prevalence at the population level. These weightings were added with help of information from the registers of the total population of Gävleborg County. Furthermore, apart from adjustments for the sample sizes in the different strata, the register data were used for calibration of nonresponse bias for various groups of individuals. ${ }^{[43-45]}$

However, the collection of data in the Health in Equal terms survey is of high quality, even if physical activity was based on people's self-report. ${ }^{[42,43]}$ In addition, the study has strengths as it used a large population sample and collected information such as self-reported health, which is known to be reliable. ${ }^{[46-48]}$

\section{Conclusion}

This study found an association between being not employed and physical inactivity. The association was explained by health and socioeconomic factors. In addition, the study found a relationship between low education, low income, and poor self-rated health with physical inactivity. However, longitudinal studies are warranted to further disentangle potential mechanisms behind the observed association between employment status and physical (e.g., the effects of neighborhoods and availability of leisure infrastructures). From the policy perspective, our study suggests the need to promote physical activity during times of high unemployment in order to foster better health behaviors.

\section{References}

1. An R, Liu J. Local labor market fluctuations and physical activity among adults in the United States 1990-2009. Int Schol Res Network Public Health 2012; pp. 1-7.

2. Marcus J. Does Job Loss Make You Gain Weight? SOE Papers on Multidisciplinary Panel Data Research. Berlin, Germany: Ministry of Health, Labour and Welfare, 2002. pp. 1-26. No.432.

3. OECD. Employment Outlook 2010: Moving Beyond the Jobs Crisis. Paris, France: OECD, 2010.

4. Gough M. A couple-level analysis of unemployment and health behaviors. Presented at the Conference of the Population Association of America; 2013; New Orleans, LA, pp. 1-3.

5. Kan M. How does unemployment affect health-related behaviour of Japanese men: a panel data analysis? School of Economics, University of Hyogo, 2010. pp. 1-28.

6. Ludwig DS, Pollack HA. Obesity and the economy from crisis to opportunity. JAMA 2009;301(5):533-5.

7. Sullivan DG, von Wachter T. Job displacement and mortality: an analysis using administrative data. Q J Econ 2009; 124(3):1265-306.

8. Ruhm CJ. Are recessions good for your health? Q J Econ 2000;15:617-650.

9. Kapuvary V. Psychological effects of economic recession and unemployment. Eur J Ment Health 2011;6:83-93.

10. Henkel D. Unemployment and substance use: a review of the literature (1920-2010). Curr Drug Abuse Rev 2011;4(1):4-27. 
11. Montgomery S, Cook D, Bartley M, Wadsworth M. Unemployment, cigarette smoking, alcohol consumption and body weight in young British men. Eur J Public Health 2002;8:21-7.

12. Falba T, Teng HM, Sindelar JL, Gallo WT. The effect of involuntary job loss on smoking intensity and relapse. Addiction 2005;100(9):1330-9.

13. Deb P, Gallo WT, Ayyagari P, Fletcher JM, Sindelar JL. The effect of job loss on overweight and drinking. J Econ 2011;30: 317-27.

14. Adam TC, Epel ES. Stress, eating and the reward system. Physiol Behav 2007;91(4):449-58.

15. Roshannei-Moghaddam B, Katon WJ, Russo J. The longitudinal effects of depression on physical activity. Gen Hosp Psychiatry 2009;31(4):306-15.

16. Sallis JF, Bowles HR, Bauman A, Ainsworth BE, Bull FC, Craig CL, et al. Neighborhood environments and physical activity among adults in 11 countries. Am J Prev Med 2009;36(6):484-90.

17. Ruhm CJ. Healthy living in hard times. J Health Econ 2005;24:341-63.

18. Charles KK, DeCicca. Local labor market fluctuations and health: is there a connection and for whom? J Health Econ 2008;27(6):1532-50.

19. Lindström M, Hanson BS, Östergren PO. Socioeconomic differences in leisure-time physical activity: the role of social participation and social capital in shaping health related behaviours. Soc Sci Med 2001;52(3):441-51.

20. Melin R, Fugl-Meyer KS, Fugl-Meyer AR. Life satisfaction in 18- to 64-year-old Swedes in relation to education, employment situation, health and physical activity. J Rehabil Med 2003; 35(2):84-90.

21. Gävle ABF. Landets högsta arbetslöshet och lägsta utbildning. Arbetsformedlingen 2012; pp. 1-4.

22. Samhälsmedicin Gävleborg. Gävleborg Folkhälsolägat (In Swedish) 2010.

23. SPSS version 20. North Carolina: SPSS Institute, 2012.

24. Wadsworthx ME. Changing social factors and their long-term implications for health. Br Med Bull 1997;53(1):198-209.

25. Mclnnes MM, Shinogle JA. Physical Activity: Economic and Policy Factors. National Bureau of Economic Research (NBER) working paper. Chicago: University of Chicago Press, 2009. pp. $1-42$.

26. Lunn P. Fair Play? Sport and Social Disadvantage in Ireland. Dublin: Economical and Social Research Institute, 2007. pp. 1-95.

27. van Oort FV, van Lenthe FJ, Mackenbach JP. Coocurrence of lifestyle risk factors and the explanation of education inequalities in mortality: results from the GLOBE study. Prev Med 2004;39(6):1126-34.

28. Owen N, Humpel N, Leslie E, Bauman A, Sallis JF. Understanding environmental influences on walking: review and research agenda. Am J Prev Med 2004;27(1):67-76.

29. Emmons KM, Barbeau EM, Gutheil CS, Stryker JE, Stoddard AM. Social influences, social context, and health behaviours among working-class, multi-ethnic adults. Health Educa Behav 2007;34(2):315-34.

30. Hyytinen A, Lahtonen J. The effect of physical activity on longterm income. Soc Sci Med 2013;96:129-37.

31. Jankovic J, Janevic T, von dem Knesebeck O. Socioeconomic inequalities, health damaging behaviour, and self-perceived health in Serbia: a cross-sectional study. Croat Med J 2012; 53(3):254-62.

32. Nicholson S, Simon K. How did the recession affect health and related activities of Americans? 2010. Available at: http://www. unc.edu/the/archives/simon.pdf
33. Bauman A, Bull F. Physical Activity: Correlates and Interventions. School of Sports and Exercise Science, Lougborough University 2007. pp. 1-44.

34. Schunck R, Rogge BG. Unemployment and its association with health-relevant actions investigating the role of the time perspective with German census data. Int J Public Health 2010;55(4):271-8.

35. Trost S, Owen N, Bauman AE, Sallis JF, Brown W. Correlates of adult participation in physical activity: review and update. Med Sci Sports Exerc 2002;34(12):1996-2001.

36. Resnick B, Orwig D, Magaziner J, Wynne C. The effect of social support on exercise behavior in older adults. Clin Nurs Res 2002;11(1):52-70.

37. Charilaou M, Karela M, Constantinou M, Price S. Relationship between physical activity and type of smoking behaviour among adolescents and young adults in Cyprus. Nicotine Tob Res 2009;11(8):969-76.

38. Papathanasiou G, Papandreou M, Galanos A, Kortianou E, Tsepis E, Kalfakakou V, et al. Smoking and physical activity interrelations in health science students. Is smoking associated with physical inactivity in young adults? Hellenic J Cardiol 2012;53(1):17-25.

39. Abu-Omar K, Rutten A, Robine JM. Self-rated health and physical activity in the European Union. Soz Praventivmed 2004;49(4):235-42.

40. Ker J, Sallis JF, Saelens BE, Cain KL, Conway TL, Frank LD, et al. Outdor physical activity and self-rated health in older adults living in two regions of the US. Int $\mathrm{J}$ Behav Nutr Phys Act 2012;9:89.

41. LaMonte MJ, A insworth BE. Quantifying energy expenditure and physical activity in the context of dose response. Med Sci Sports Exerc 2001;33(Suppl 6):S370-8.

42. Boström B, Nyqvist K. Objective and Background of Questions in the National Public Health Survey. Swedish National Institute of Public Health, Sweden:2010:2. pp. 1-75.

43. Statistics Sweden. Health on Equal Terms. Survey 2010. County: Gävleborg County Council Technical Report (In Swedish), 2010. pp. 1-61.

44. Lundström S, Särndal C. Calibration as a standard method for treatment of nonresponse. J Off Stat Stockholm 1999;15:305-28.

45. Särndal CE, Lundström S. Estimation in Surveys with Nonresponse. Chichester, England: Wiley, 2005. pp. 1-195.

46. Jylhä M. What is self-rated health and why does it predict mortality? Towards a unified conceptual model. Soc Sci Med 2009;69(3):307-16.

47. Miilunpalo S, Vuori I, Oja P, Pasanen M, Urponen H. Self-rated health status as a health measure: the predictive value of self-reported health status on the use of physician services and on mortality in the working-age population. J Clin Epidemiol 1997;50(5):517-28.

48. Wu S, Wang R, Zhao Y, Ma X, Wu M, Yan X, et al. The relationship between self-rated health and objective health status: a population-based study. BMC Public Health 2013;13:320.

How to cite this article: Macassa G, Ahmadi N, Alfredsson J, Barros H, Soares J, Stankunas M. Employment status and differences in physical activity behavior during times of economic hardship: results of a population-based study. Int J Med Sci Public Health 2016;5 (Online First). DOI: 10.5455/ijmsph.2016.0101201515 Source of Support: Nil, Conflict of Interest: None declared. 